\title{
Izod impact energy study of re-forced polisher matrix compounds with curaous fibers aligned and epoxy matrix reinforced with piassava fibers
}

\author{
Ailton da Silva Ferreira ${ }^{1}$, Denise Cristina de Oliveira Nascimento ${ }^{2}$, \\ Sergio Neves Monteiro ${ }^{3}$
}

\footnotetext{
${ }^{1,2}$ Curso de Administração, UFF - Universidade Federal Fluminense, Macaé, Rio de Janeiro, Brasil.

${ }^{3}$ IME- Instituto Militar de Engenharia, Rio de Janeiro, Rio de Janeiro, Brasil.

e-mail: ailtonsilvaferreira@yahoo.com.br, denise_cristin@yahoo.com.br, snevesmonteiro@gmail.com
}

\begin{abstract}
Polymer matrix composites have been applied in components such as helmets and shielding for which toughness is a major requirement. Natural fiber presents interfacial characteristics with polymeric matrices that favor a high impact energy absorption by the composite structure. The objective of this work was then to assess the Izod impact resistance of polymeric composites reinforced with different amounts, up to $30 \%$ in volume, of a promising high strength natural fiber from the Amazon region known as curaua. Among these, the piassava fiber extracted from a palm tree native of South America stands as one of the most rigid with a potential to be used as composite reinforcement. Therefore, the present work investigates the notch toughness behavior, by Izod impact tests, of epoxy composites reinforced with up to $40 \%$ in volume of continuous and aligned piassava fibers. The results showed a remarkable increase in the notch toughness with the amount of incorporated curaua fibers. This can be attributed to a preferential debonding of the fiber/matrix interface, which contributes to an elevated absorbed energy. . It was found that the incorporation of piassava fibers results in significant increase in the impact energy of the composite. Scanning electron microscopy analysis showed that the nature of the piassava fiber interface with the epoxy matrix is the major responsible for the superior toughness of the composite.
\end{abstract}

Keywords:Piassava, curauá, polymer matrix, epoxy matriz, Izod, .

\section{INTRODUCTION}

Natural fibers, especially those lignocellulosic obtained from plants, offer economical environmental and technical advantages in comparison to synthetic fibers for application as the reinforcement of polymeric composites [1-3, 33, 40, 46]. Some of these lignocellulosic fibers like jute, sisal, cotton, flax, hemp, coconut and sawdust are, since long time, being added to polymers to enhance the properties [4]. This historical fact dates back to the first industrial polymer, the Bakelite, which was more than one hundred years ago incorporated with sawdust to improve its impact resistance and reduce cost [2-5]. For the industry, low cost is certainly an important incentive associated with the use of lignocellulosic fibers that usually have a commercial price around five times lower than that of glass fiber, the cheapest among the synthetic fibers.

Environmental issues are, additionally gaining attention owing to worldwide problems related to climate changes and pollution. This is nowadays a major advantage for the natural fibers that are renewable, biodegradable and recyclable. By contrast to glass fiber composites that cannot be recovered, natural fiber composites can be completely burnt to produce energy [6]. Moreover, lignocellulosic fibers are neutral with respect to $\mathrm{CO}_{2}$ emission, the main responsible for global warming [7, 46, 47].

Technical advantages are also associated with the use of lignocellulosic fibers in polymeric composites. According to Zah et al. [5], the application of natural fiber composites is rapidly increasing in the automobile industry with annual growth rates above $20 \%$. Both interior and exterior components are already on the market and a major reason is the technical advantage of a higher impact resistance. This is of great importance in case of a crash event and applies equally for an automobile head rest or a cyclist helmet.

Earlier works $[8,9,46,47]$ on impact resistance of polymeric composites were conducted with different short-cut randomly oriented lignocellulosic fiber reinforcement. In these works, Izod impact tests with notched and fixed specimens resulted in absorbed energy values lower than $60 \mathrm{~J} / \mathrm{m}$ for all fibers investigated 
as polypropylene composite reinforcement. Recent works on the impact resistance of thermoset polymer composites reinforced with long and aligned lignocellulosic fibers [10-15], revealed a much higher value for the impact energy. In particular, a polyester composite reinforced with $40 \%$ of curaua fiber reached $170 \mathrm{~J} / \mathrm{m}$ [11], which is more than three times the maximum obtained by any short-cut and randomly oriented lignocellulosic fiber composites [9]. This remarkable result served as motivation for a work to confirm it with a different impact method, the Charpy test.

According to the ASTM D 256 norm, there are significant differences between both tests, Charpy and Izod [15] that could lead to distinct results. These differences are shown in Fig.1.

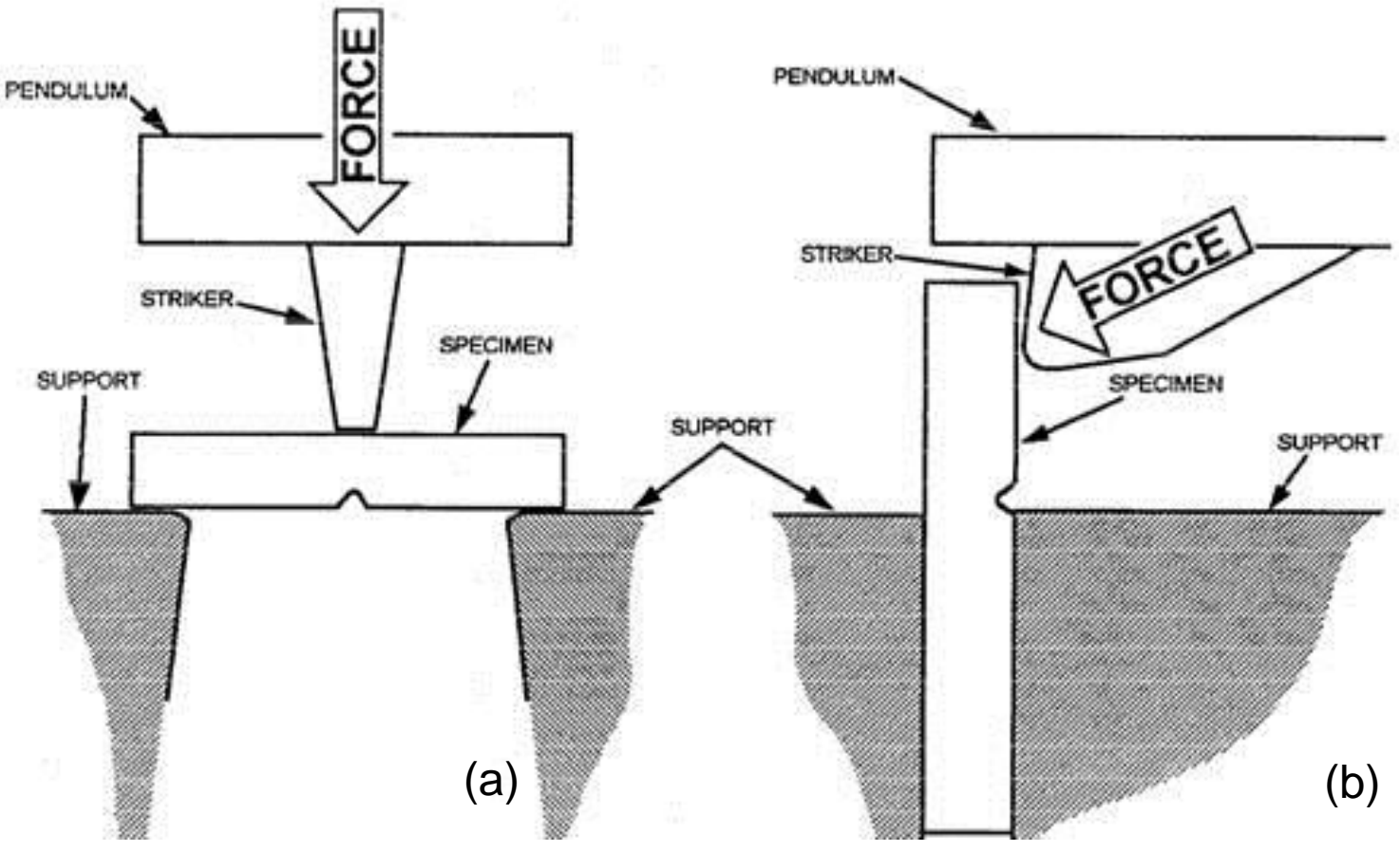

Figure 1: The Charpy (a) and the Izod (b) impact test methods.

Synthetic fibers such as glass, carbon and aramid have been primary used as composite reinforcement in practically all technological segments. Light-weight components for automobile, boats and planes are typical examples of applications for synthetic fiber polymer matrix composites to attend specifications of structure and mechanical performance. Toughness, in particular is an important requirement for composite components that have to sustain impact forces during a crash event. These synthetic composites, however, are non-recyclable and the fabrication methods for fiber production are energy intensive. Until recently, such points were not of great relevance but nowadays both energy and environmental questions are being raised by a concerning part of our society [16].

The consequences of climate changes and the increase in the price of petroleum are motivating the use of natural materials as substitute for energy intensive synthetic materials [17]. In particular, natural cellulosebased fibers obtained both, from cultivated plants such as jute, sisal, hemp and flax as well as those from industrial waste such as sugar cane bagasse and coconut husk are being considered to replace synthetic glass fibers $[18,19]$. In addition of their abundance, lignocellulosic fibers, present the comparative advantages of being renewable, recyclable and biodegradable. Moreover, lignocellulosic fibers require less amount of processing energy and are neutral with respect to $\mathrm{CO}_{2}$ emission, which causes the atmospheric greenhouse effect responsible for the global warming [20]. Low cost is another important economical advantage of the natural fibers over the synthetic ones and the application of lignocellulosic is also associated with a lower equipment wearing and better finishing of molded components [21]. Moreover, for some fibers, properties such as the mechanical strength and impact resistance can be superiors to the corresponding properties of synthetic glass fiber [22]. The characteristics and properties of several lignocellulosic fibers are, nowadays being extensively discussed in the literature. However, there are still less known fibers with great potential as engineering material that deserves investigation [41]. 


\section{MATERIALS AND METHODS}

This figure reveals that the Charpy specimen, with a minimum length of $124 \mathrm{~mm}$, is free-standing on the support during the impact, Fig. 1(a), with a hammer, which strikes exactly at the opposite side of the notch. By contrast, the Izod specimen has a maximum length of $63 \mathrm{~mm}$ and is fixed to the support during the impact, Fig. 1(b), which strikes at a point $22 \mathrm{~mm}$ away from the notch. In practice, the Izod test simulates better the actual situation of a component fixed into a system, which is hit at a point away from a stress raiser like a grove or a flange.

Base on these considerations, the objective of the present work was to assess the impact resistance, by means of Izod tests, of polymeric composites reinforced with different amounts of curaua fibers.

The curaua fiber was obtained from the Amazon Paper, a firm that commercializes natural fibers cultivated in the north of Brazil. The typical aspect of a curaua plantation and a bundle of soft fibers are shown in Fig. 2.
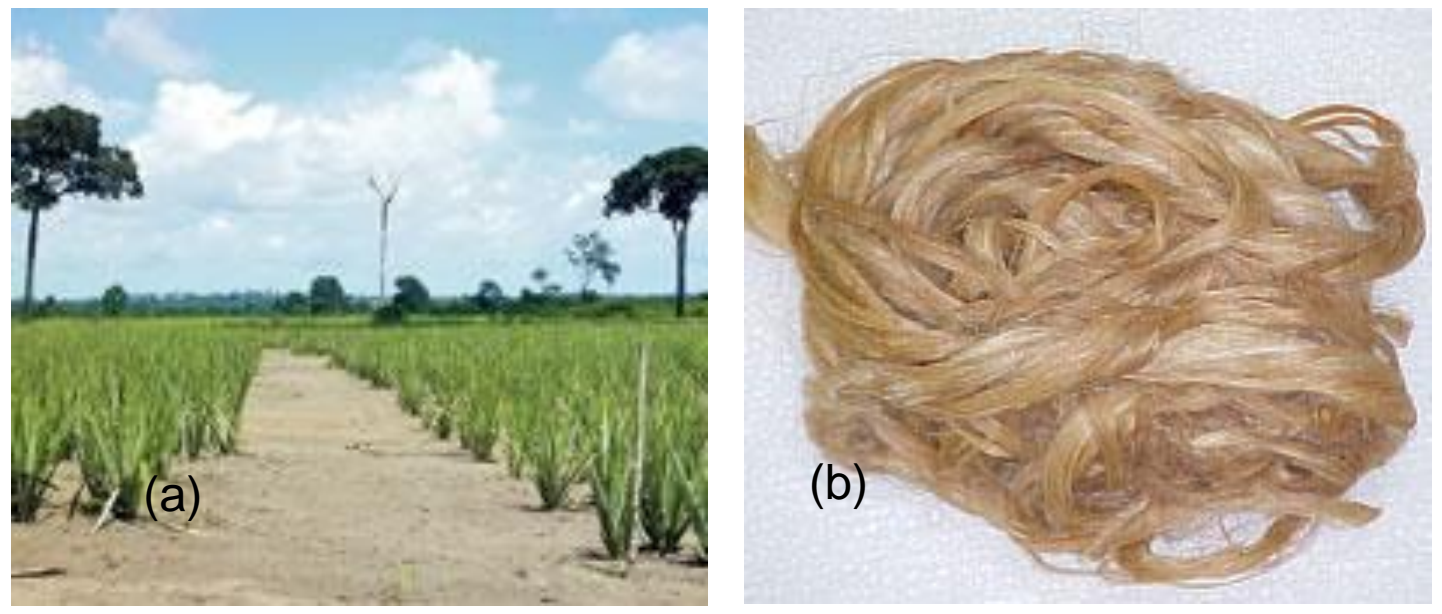

Figure 2: Curaua from the state of Para, Brazil: (a) plantation and (b) soft fibers.

From the as-received lot of curaua, one hundred fibers were separated for a statistic dimensional analysis. The distribution of length and diameter is presented in Fig. 3. This figure reveals that dimensions of the curaua fibers as any other lignocellulosic fiber [1-3,42], are heterogeneous with a significant dispersion in values. Another relevant information from Fig. 3 is that the average length of the fibers, calculated as 846 $\mathrm{mm}$, is more than 15 times its critical length of $10.2 \mathrm{~mm}$ [34]. This is considered a condition for long fiber in terms of composite reinforcement and assures an effective strengthening of the matrix [35].
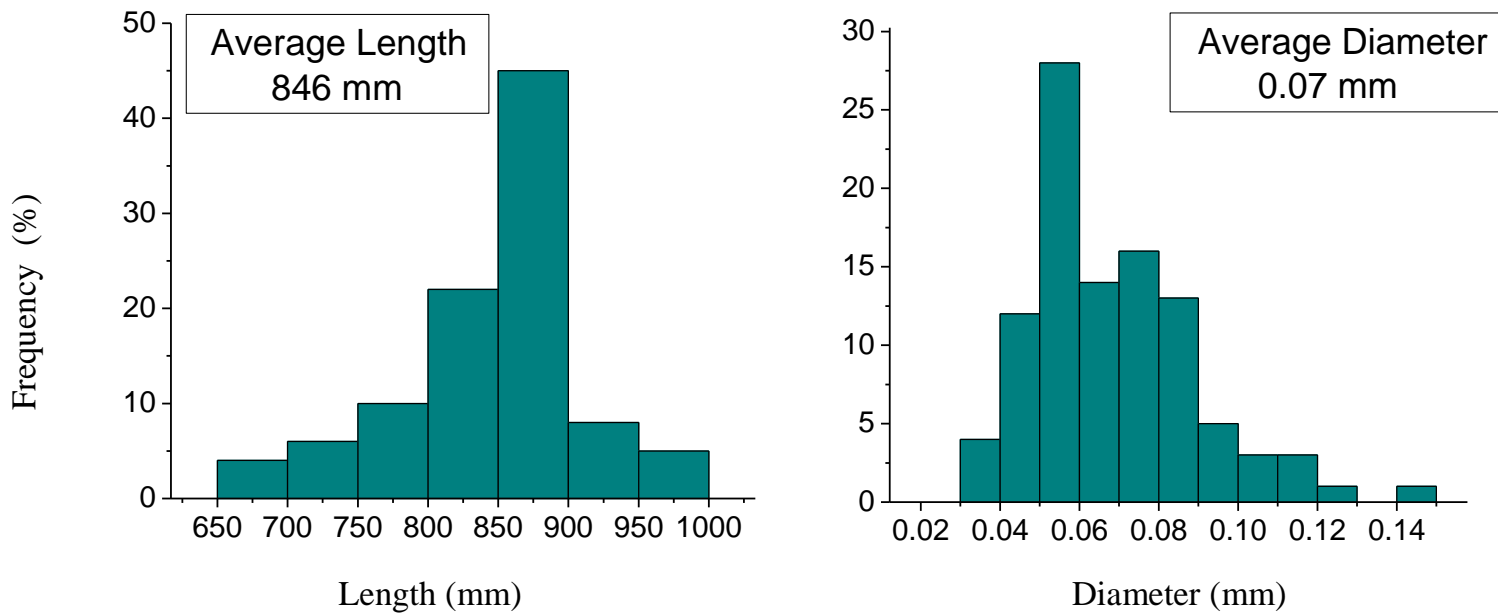

Figure 3: Histogram of the statistical distribution of (a) length and (b) diameter of curaua fibers.

After cleaning and room temperature (RT) drying, aligned curaua fibers were mixed in amounts of 0 , $5,10,15,20,25$ and $30 \%$ in volume with a commercial ortophtalic polyester resin added with $0.5 \%$ metylethyl-ketone hardener. Plates of these composites were press molded and allowed to cure at RT for 24 hours. 
Standard notched specimens, $63 \times 12.7 \times 10 \mathrm{~mm}$ for Izod impact testing, according to the ASTM D256 norm, were cut from the plate along the direction of alignment of the fibers. The notch with $2.54 \mathrm{~mm}$ in depth, angle of $45^{\circ}$ and a tip curvature radius of 0.25 was machined according to DIN 847 norm. For each condition, 10 specimens were tested to assure a statistical validation. The specimens were impact tested with a EMIC hammer pendulum. The impact energy was obtained with $2.7 \mathrm{~J}$ hammer for the pure polyester specimens up to $20 \%$ curaua fiber, and with a $5.4 \mathrm{~J}$ hammer for the 25 and $30 \%$ curaua fiber composites.

The impact fracture surface of the specimens was analyzed by scanning electron microscopy, SEM in a model JSM-6460 LV Jeol microscope. Gold sputtered SEM samples were observed with secondary electrons imaging at $15 \mathrm{kV}$.

Piassava fibers, extracted from the leaves of a palm tree, Fig. 4(a), native of the state of Bahia, in the southeast region of Brazil, are a very promising candidate to reinforce polymeric matrices to fabricate stiff composites [23-26]. A description of the chemical characterization, properties and morphological aspects of the long and hard type (Attalea funifera Mart) of piassava has been given elsewhere [25]. All previously reported works on piassava reinforced composites [23-24], have used polyester as matrix. It was found that the impact resistance of continuous and aligned piassava fiber/polyester composites was superior to the values of other short-cut lignocellulosic fiber/polymeric composites [27]. The promising properties of piassa$\mathrm{va}$ /polyester composites motivated the study of different polymeric matrices. Epoxy is another possibility of thermoset polymeric matrix with similar strength and cost with respect to polyester. Therefore, the present work investigates the notch toughness behavior, by means of the impact energy obtained in Izod tests, of epoxy composites reinforced with different volume fractions of continuous and aligned piassava fibers.
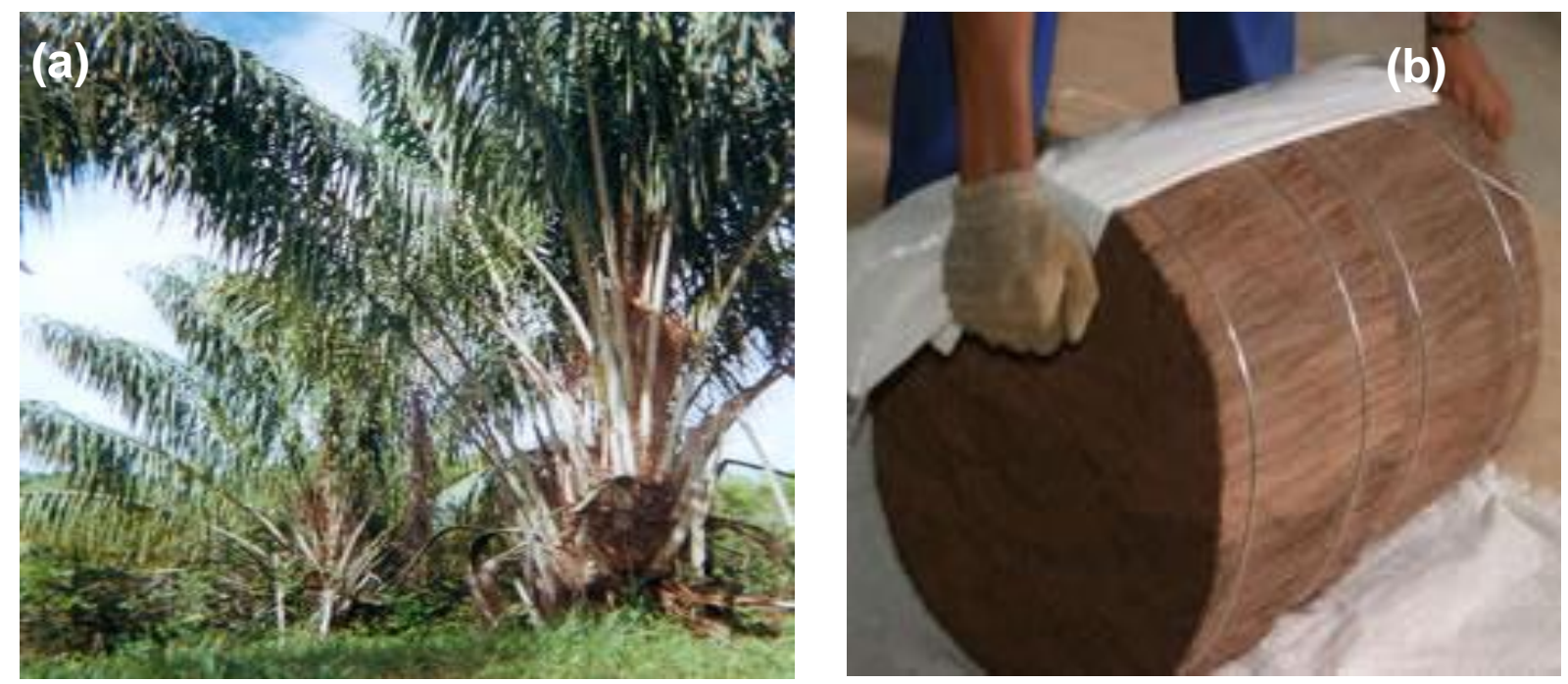

Figure 4: (a) Piassava palm trees in the state of Bahia; (b) cut piassava fibers being wrapped.

The piassava fibers used in this work were obtained as residuals, as illustrated in Fig. 4(b), from a broom industry in Campos dos Goytacazes, state of Rio de Janeiro, Brazil. They were undamaged and long enough to be used as aligned reinforcement phase in epoxy composites. Figure 5 shows the distribution of the length and diameter from a statistical analysis performed in a lot with 100 fibers. The total average length was $454.64 \mathrm{~mm}$ and average diameter $0.92 \mathrm{~mm}$. The commercial epoxy used as composite matrix was a stoichiometric, phr13, diglycidyl ether of the bisphenol-A (DGEBA) resin mixed with a triethhylene tetramine (TETA) hardener. Composites plates were fabricated by press-molding the still liquid DGEBA/TETA epoxy with the piassava fibers.

Here it is worth mentioning that the critical length obtained in pullout tests for piassava fibers was $\boldsymbol{\ell}_{\mathbf{c}}=$ $15 \mathrm{~mm}$ [8]. A comparison with the average length of $\mathrm{L}=455$ and the minimum of $250 \mathrm{~mm}$ in the statistical distribution, Fig. 5, indicates that all fibers investigated have $\mathrm{L}>15 \boldsymbol{\ell}_{\mathbf{c}}$ and, consequently, are considered long and continuous [13]. 


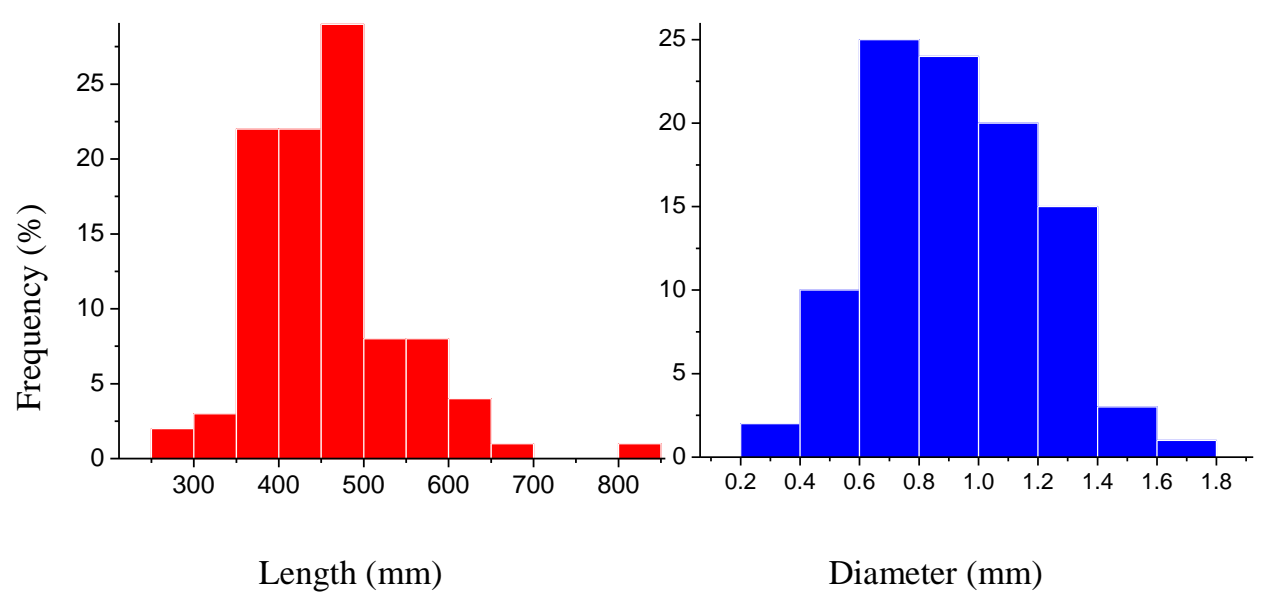

Figure 5: Statistical distribution of length and diameter of the lot of piassava fibers for this work.

The composites were prepared by pouring the polyester resin to composites with curauá fibers and epoxy resins to those with the piaçava fibers on the fibers disposed in the mold. Composites with fiber fractions ranging from 0 to $50 \%$ were produced in volumetric fraction, and the fibers were arranged in the longitudinal and / or transverse-salt directions to the mold. The reinforcement of a polymeric matrix with synthetic and natural fibers increases the hardness of the impact of the compound [43]

It should be explained that this stoichiometric ratio in principle corresponds, for the polyester, to the indication of the manufacturer and, for the epoxy resin, to the opening of all the epoxy rings by bonding with the amine molecules $[44,45]$.

The rectangular plates of these composites measuring $152 \times 122 \times 10 \mathrm{~mm}$ were fabricated in a closed steel mold. The complementary amount is that of the said resin mixed with the catalyst, but still in the liquid state, being mixed with the fibers. During the curing, a one tonne load was applied over the mold cap to facilitate impregnation of the resin between the fibers.

Each plate, after curing, was made up of 9 specimens measuring $62 \times 12 \times 10 \mathrm{~mm}$ for the Izod test, according to ASTM D256. Figure 6 shows the matrix used to perform the assays.
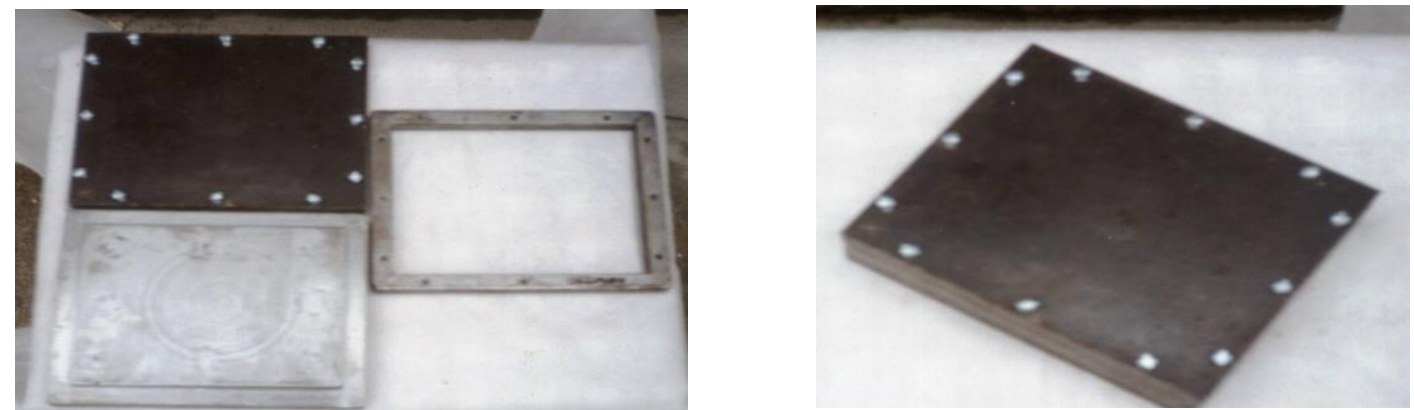

Figure 6: Matrix to be used for compaction of flexural test bodies.

For the preparation of the notch with a depth of $2.54 \mathrm{~mm}, \mathrm{a} 45^{\circ}$ angle and a radius of curvature of $0.25 \mathrm{~mm}$ at the bottom of the notch, a German high speed milling cutter was used, according to DIN 847 in figure 7 (a). The specimens were tested in an EMIC pendulum, in an Izod configuration, belonging to the Institute of Xistoquímica of UFRJ. Figure 7 (b) presents an image of the impactor used in the impact resistance measurements of the composites studied. 


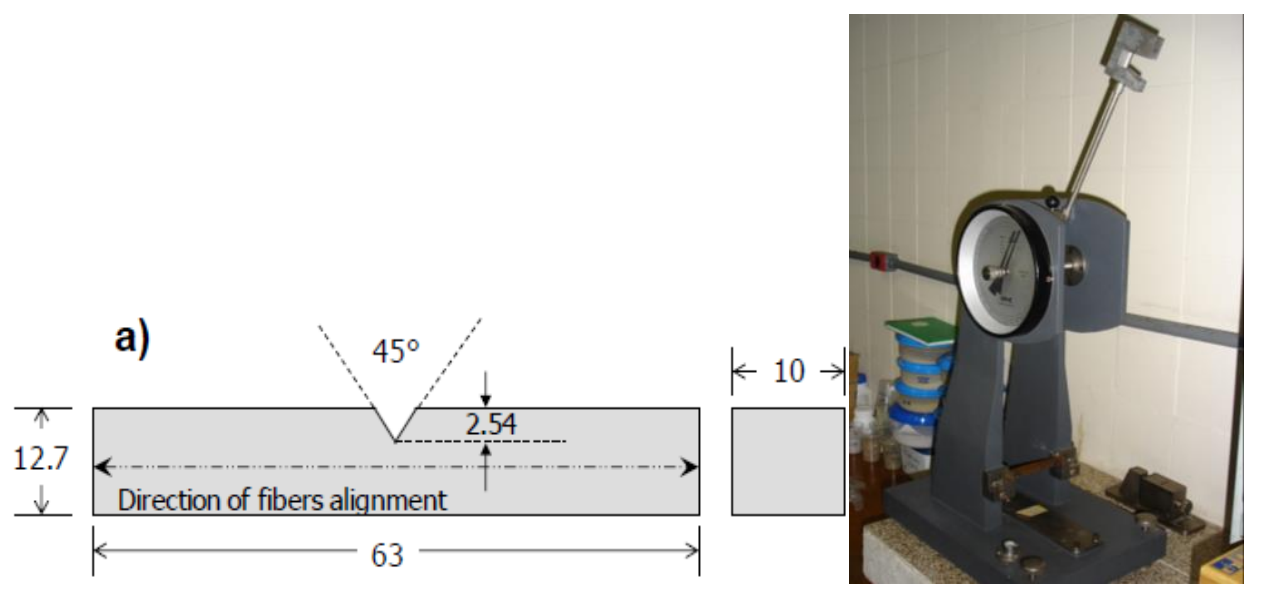

Figure 7: Schematic of the Charpy and Izod test body (a) and E-MIC impact impactor (b).

\section{RESULTS AND DISCUSSION}

The variation of the Izod impact energy with the amount of curaua fiber in the polyester composite is shown in Fig. 8.

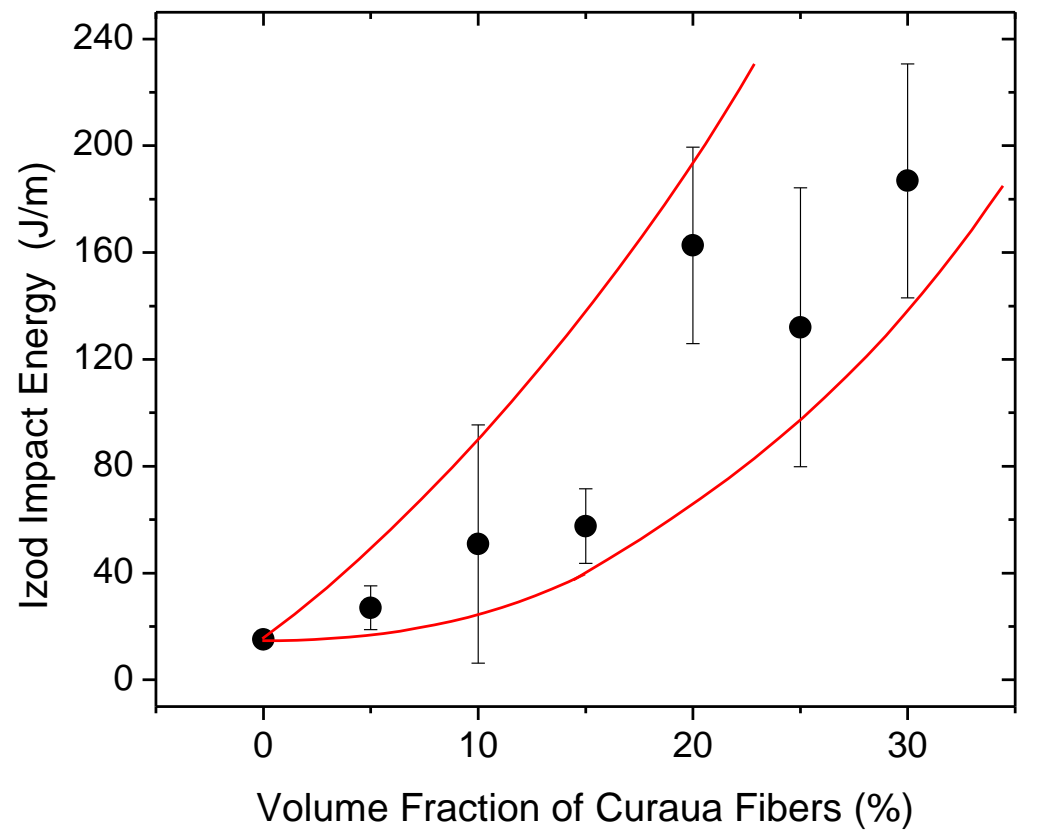

Figure 8: Izod impact energy as a function of the amount of curaua fibers.

In this figure it should be noticed that the curaua fiber incorporation into the polyester matrix significantly improves the impact toughness of the composite. Within the standard deviation, this improvement can be considered as an exponential function with respect to the amount of curaua fiber up to $30 \%$. The relatively high dispersion of values, given by the error bars associated with the higher fiber percentage points in Fig. 8, highlighted by red lines, is a well known non-uniform characteristic of the lignocellulosic fibers [2]. The values shown in this figure are consistent with results reported in the literature. The reinforcement of a polymeric matrix with both synthetic [36] and natural [8,37] fibers increases the impact toughness of the composite. Table I compares values of impact toughness of polymeric composites with different natural fibers.

The variation of the Izod impact energy with the amount of piassava fiber in the epoxy composite is shown in Fig. 9. 


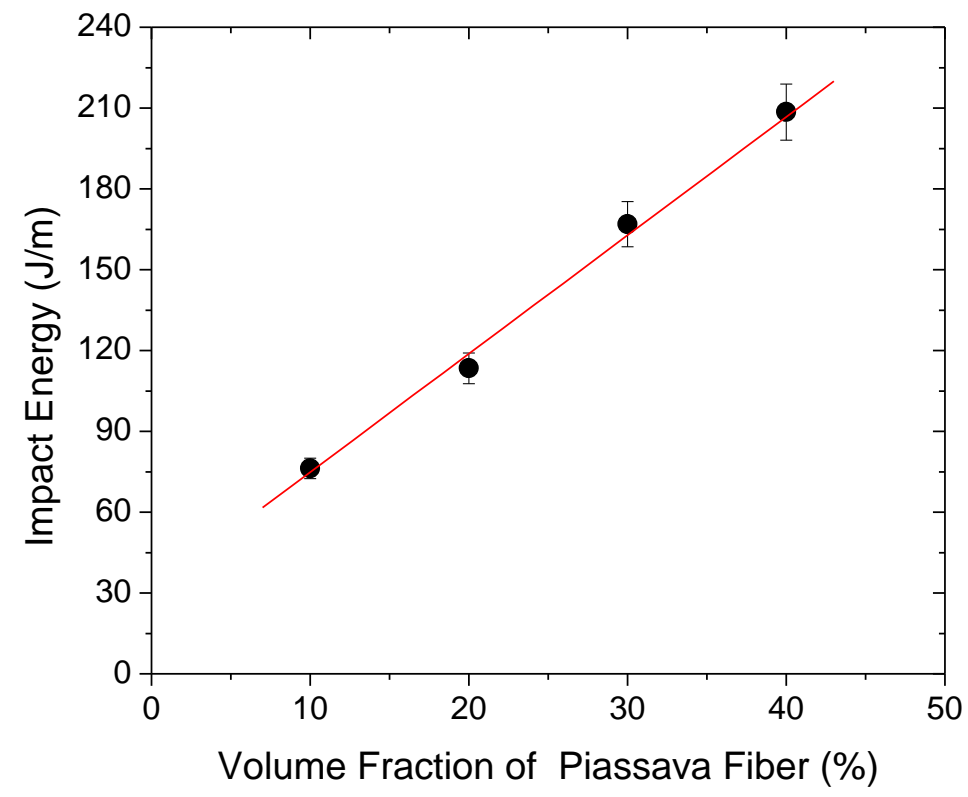

Figure 9: Izod impact energy as a function of the amount of piassava fibers.

In this figure it should be noticed that the piassava fiber incorporation into the epoxy matrix significantly improves the impact toughness of the composite. Within the standard deviation, this improvement can be considered as a linear function with respect to the amount of piassava fiber up to $40 \%$. The values shown in this figure are consistent with results reported in the literature. The reinforcement of a polymeric matrix with both synthetic [29] and natural [26,30] fibers increases the impact toughness of the composite. Table I compares values of impact toughness of polymeric composites with different natural fibers.

In this work, using long and aligned curaua fibers, the impact toughness is significantly higher than the values reported for polypropylene composites reinforced with $50 \%$ of short cut and randomly oriented lignocellulosic fibers. The greater impact resistance of the polyester in comparison with the polypropylene matrix could be one reason for the superior performance of the present result. However, there are other important factors related to the impact fracture characteristic of polymeric reinforced with long and aligned natural fibers.

Table 1: Impact toughness of polymeric composites reinforced with natural fibers.

\begin{tabular}{|c|c|c|c|c|}
\hline Composite & $\begin{array}{c}\text { Amount of Fiber } \\
(\%)\end{array}$ & $\begin{array}{c}\text { Fiber Condition in } \\
\text { the Composite }\end{array}$ & $\begin{array}{c}\text { Izod Impact Tough- } \\
\text { ness }(\mathrm{J} / \mathrm{m})\end{array}$ & Reference \\
\hline Jute/Polypropylene & 50 & $\begin{array}{c}\text { Short-cut randomly } \\
\text { oriented }\end{array}$ & 39 & {$[8,30]$} \\
\hline Sisal/ Polypropylene & 50 & $\begin{array}{c}\text { Short-cut randomly } \\
\text { oriented }\end{array}$ & 51 & {$[8,30]$} \\
\hline Flax/ Polypropylene & 50 & $\begin{array}{c}\text { Short-cut randomly } \\
\text { oriented }\end{array}$ & 38 & {$[8,30]$} \\
\hline Wood/ Polypropylene & 50 & $\begin{array}{c}\text { Short-cut randomly } \\
\text { oriented }\end{array}$ & 28 & {$[8,30]$} \\
\hline Curaua/ Polypropylene & 50 & $\begin{array}{c}\text { Short-cut randomly } \\
\text { oriented }\end{array}$ & 54 & {$[8,30]$} \\
\hline Coir/ Polypropylene & 50 & $\begin{array}{c}\text { Short-cut randomly } \\
\text { oriented }\end{array}$ & 46 & {$[8,30]$} \\
\hline Coir/polyester & 40 & Long and aligned & 121 & {$[31,38]$} \\
\hline Curaua/polyester & 30 & Long and aligned & 190 & this work \\
\hline Piassava/epoxy & 30 & Long and aligned & 209 & this work \\
\hline
\end{tabular}


The relatively low interface strength between a hydrophilic natural fiber and a hydrophobic polymeric matrix contributes to an ineffective load transfer from the matrix to a longer fiber. This results in relatively greater fracture surface and higher impact energy needed for the rupture [39]. Another factor is the flexural compliance of a long fiber during the impact test, which will be further discussed.

The incorporation of long and aligned curaua fibers results in a marked change with respect to pure polyester $(0 \%$ fiber) in which a totally transversal rupture occurs. Even with $10 \%$ of fiber, the rupture is no longer completely transversal. This indicates that the cracks nucleated at the notch will initially propagate transversally through the polyester matrix, as expected in a monolithic polymer. However, when the crack front reaches a fiber, the rupture will proceed through the interface. As a consequence, after the Izod hammer hit the specimen, some long fibers will be pulled out from the matrix but, owing to their compliance, will not break but simply bend. In fact, for amounts of fiber above $10 \%$, the specimens are not separated at all. For these amounts of long curaua fibers, part of the specimen was bent enough to allow the hammer to continue its trajectory without carrying away the top part of the specimen, as expected in a Izod test. The value of the impact toughness in this case cannot be compared with others in which the specimen is totally split apart. Anyway, the fact that a specimen is not completely separated in two parts underestimates the impact toughness. In other words, had all the fibers been broken, the adsorbed impact energy would be higher.

In this work, using long and aligned piassava fibers, the impact toughness is significantly higher than the values reported for polypropylene composites reinforced with $50 \%$ of short cut and randomly oriented lignocellulosic fibers. The greater impact resistance of the epoxy in comparison with the polypropylene matrix could be one reason for the superior performance found in the present work. However, there are other important factors related to the impact fracture characteristic of polymeric reinforced with long and aligned natural fibers.

The relatively low interface strength between a hydrophilic natural fiber and a hydrophobic polymeric matrix contributes to an ineffective load transfer from the matrix to a longer fiber. This results in relatively greater fracture surface and higher impact energy needed for the rupture [30].

The incorporation of long and aligned piassava fibers results in a marked change with respect to pure epoxy ( $0 \%$ fiber) in which a totally transversal rupture occurs. Even with $10 \%$ of fiber, the rupture is no longer completely transversal. This indicates that the cracks nucleated at the notch will initially propagate transversally through the epoxy matrix, as expected in a monolithic polymer. However, when the crack front reaches a fiber, the rupture will proceed through the interface. As a consequence, after the Izod hammer hit the specimen, some long fibers will be pulled out from the matrix but, owing to their compliance, will not break but simply bend. In fact, for amounts of fiber above $10 \%$, the specimens are not separated at all. For these amounts of long piassava fibers, part of the specimen was bent enough to allow the hammer to continue its trajectory without carrying away the top part of the specimen, as expected in an Izod test. The value of the impact toughness in this case cannot be compared with others in which the specimen is totally split apart. Anyway, the fact that a specimen is not completely separated in two parts underestimates the impact toughness. In other words, had all the fibers been broken, the adsorbed impact energy would be even higher.

The SEM analysis of the Izod impact fracture permitted to have a better comprehension of the mechanism responsible for the higher toughness of polyester composites reinforced with long curaua fiber. Figure 10 shows the aspect of the fracture surface of a pure polyester $(0 \%$ fiber) specimen. With lower magnification, the upper darker layer in the fractograph, Fig 10(a), corresponds to the specimen notch, revealing the machining horizontal marks. The smoother and light gray layer underneath corresponds to the transversal fracture surface. The fracture in Fig. 10 suggests that a single crack was responsible for the rupture with the roughness in Fig 10(b), being associated with voids and imperfections during the processing. 


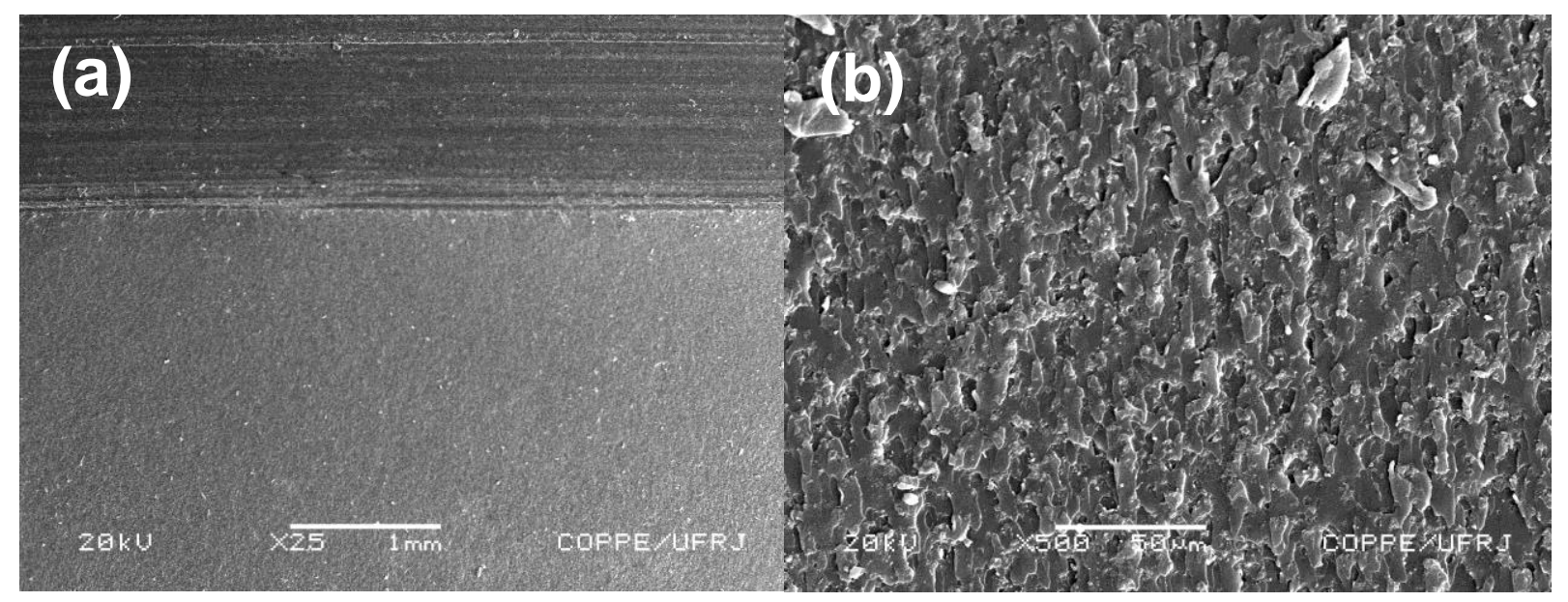

Figure 10: Izod impact fracture surface of pure polyester specimen ( $0 \%$ fiber): (a) general view; (b) detail of the polyester transversal fracture.

Figure 11 presents details of the impact fracture surface of a polyester composite specimen with $30 \%$ of curaua fibers. This fractograph shows an effective adhesion between the fibers and the polyester matrix, where cracks preferentially propagate. Some of the fibers were pulled out from the matrix and others were broken during the impact. By contrast, the part of the specimen in which the rupture preferentially occurred longitudinally through the fiber/matrix interface reveal that most of the fracture area is associated with the fiber surface.

This behavior corroborates the rupture mechanism of cracks that propagate preferentially in between the curaua fiber surface and the polyester matrix due to the low interfacial strength [38]. The greater fracture area, Fig. 9, associate with the long and aligned fibers acting as reinforcement for the composite, justify the higher absorbed impact energy, Fig. 9, with increasing amount of curaua fibers.
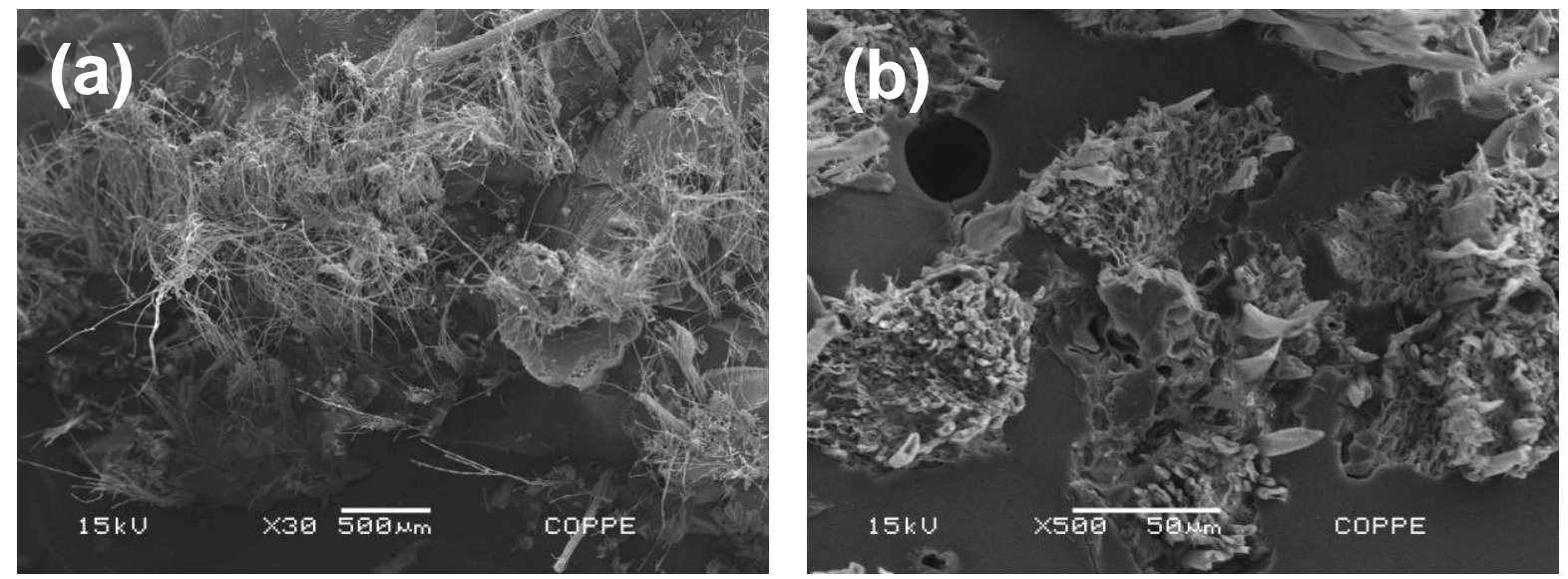

Figure 11: Impact fracture surface of a polyester composite reinforced with $30 \%$ curaua fibers: (a) $30 \mathrm{X}$ and (b) $500 \mathrm{X}$.

The SEM analysis of the Izod impact fracture permitted to have a better comprehension of the mechanism responsible for the higher toughness of epoxy composites reinforced with long piassava fiber. Figure 12 presents details of the impact fracture surface of a epoxy composite specimen with $30 \%$ of piassava fibers. This fractograph shows an effective adhesion between the fibers and the epoxy matrix, where cracks preferentially propagate. Some of the fibers were pulled out from the matrix and others were broken during the impact. By contrast, the part of the specimen in which the rupture preferentially occurred longitudinally through the fiber/matrix interface reveal that most of the fracture area is associated with the fiber surface. 


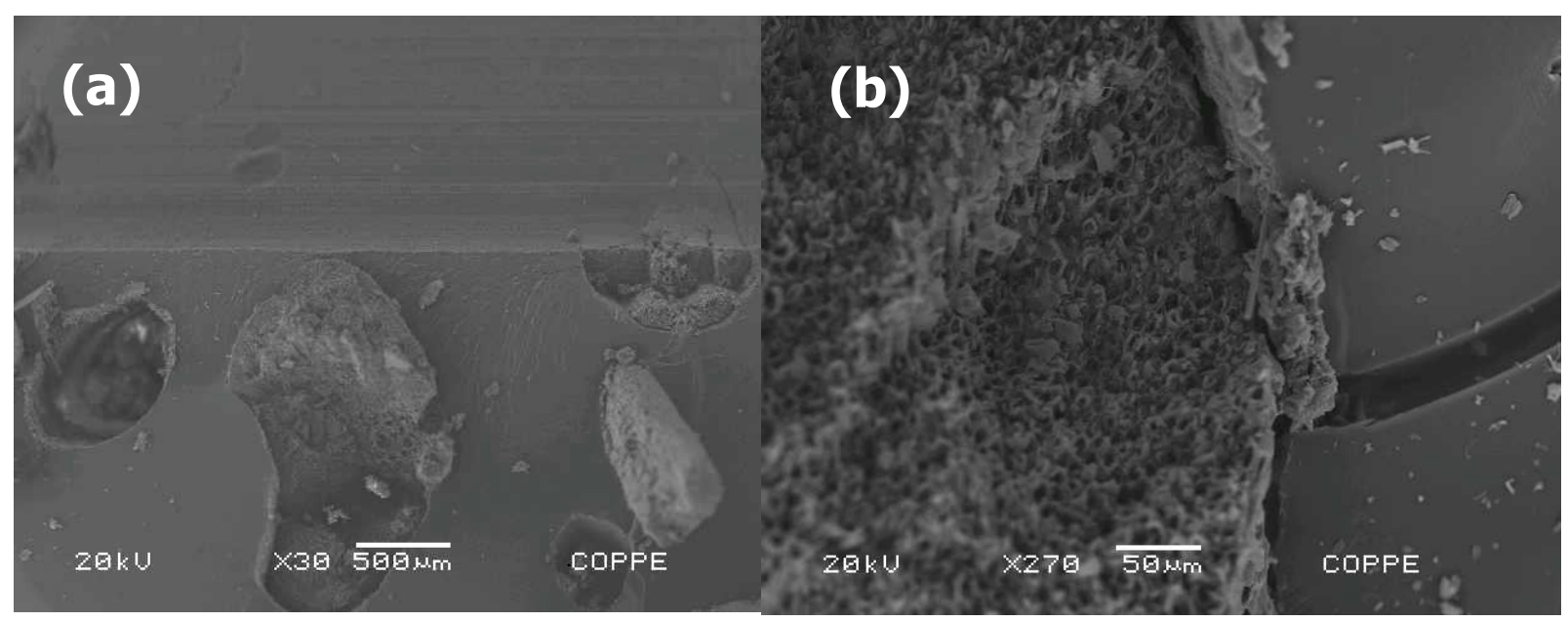

Figure 12: Impact fracture surface of an epoxy composite reinforced with $30 \%$ piassava fibers: (a) $30 \mathrm{X}$ and (b) $270 \mathrm{X}$.

This behavior corroborates the rupture mechanism of cracks that propagate preferentially in between the piassava fiber surface and the epoxy matrix due to the low interfacial strength [32]. The greater fracture area, Fig. 12, associate with the long and aligned fibers acting as reinforcement for the composite, justify the higher absorbed impact energy, Fig. 10, with increasing amount of piassava fibers.

\section{CONCLUSION}

Composites of aligned curaua fibers reinforcing a polyester matrix display a significant increase in the toughness, measures by the Izod impact test, as a function of the amount of the fiber.

Most of this increase in toughness is apparently due to the low fiber/polyester matrix interfacial shear stress. This results in a higher absorbed energy as a consequence of a longitudinal propagation of the cracks throughout the interface, which generates larger rupture areas, as compared to a transversal fracture.

Amounts of curaua fibers above $10 \%$ are associated with incomplete rupture of the specimen owing to the bend flexibility, i.e., flexural compliance, of the curaua fibers.

Composites of aligned piassava fibers reinforcing an epoxy matrix display a significant increase in the toughness, measures by the Izod impact test, as a function of the amount of the fiber.

Most of this increase in toughness is apparently due to the low fiber/epoxy matrix interfacial shear stress. This results in a higher absorbed energy as a consequence of a longitudinal propagation of the cracks throughout the interface, which generates larger rupture areas, as compared to a transversal fracture.

Amounts of piassava fibers above $20 \%$ are associated with incomplete rupture of the specimen owing to the bend flexibility, i.e., flexural compliance, of the piassava fibers.

\section{Acknowledgements}

The authors thank the support to this investigation by the Brazilian agencies: CNPq, CAPES, FAPERJ and TECNORTE/FENORTE. It is also acknowledged the permission to the use of the impact equipment of IQ/UFRJ and the SEM microscope by the PEMM from COPPE/UFRJ

\section{BIBLIOGRAPHY}

[1] SAHED, D.N., JOG, J.P., "Natural fiber polymer composites: a review", Advances in Polymer Technol., v.18, pp. 221-274, 1999.

[2] BLEDZKI, A.K., GASSAN, J. “Composites Reinforced With Cellulose-Based Fibers", Prog. Polym. Sci, v.4, pp. 221-274, 1999.

[3] MOHANTY, A.K., MISRA, M., HINRICHSEN, G., "Biofibers, biodegradable polymers and biocomposites: an overview”, Macromolecular Mat. And Engineering, v.276/277, pp.1-24, 2000. 
[4] GEORGE, J., SREEKALA, M.S., THOMAS, S., "A review on interface modification and characterization of natural fibre plastic composites", Polymer Engin. Sci., v.41, n.9, pp. 1471-1485, 2001.

[5] ZAH, R., HISCHIER, R., LEÃO, A.L., et al., "Curaua fibers in the automobile industry - A sustainability assessment", J. Cleaner Production, v.15, pp. 1032-1040, 2007.

[6] CORBIÈRE-NICOLLIER, T., GFELLER, L.B., LUNDQUIST, L., et al., "Life cycle assessment of biofibres replacing glass fibres as reinforcement in plastics", Resource, Conservation and Recycling, v.33, pp. 267-287, 2001.

[7] MOHANTY, A.K., MISRA, M., DRZAL, L.T. "Sustainable biocomposites from renewable resources: opportunities and challenges in the green material world", J. Polym. Environ., v.10, pp. 19-26, 2002.

[8] NASCIMENTO, D.C.O., MONTEIRO,S.N., MOTTA, L.C. Characterization of the toughness of piassava fiber reinforced epoxy matrix composites by Izod impact test, Proceeding of the characterization of minerals, metals \& materials, In: TMS conference, San Francisco, CA, USA, p.1-7, February 2009.

[9] LEÃO, A.L., CARASCHI, J.C., TAN, I.H., Natural polymers and agrofiber composites, São Carlos, UNESP, 2000.

[10] MONTEIRO, S.N., AQUINO, R.C.M.P., LOPES, F.P.D., et al., "Charpy impact notch toughness of piassava fibers reinforced polyester matrix composites", Materia (R.J.), v.11, n.3, pp. 204-210, 2006.

[11] MONTEIRO, S.N., LOPES, F.P.D. "Impact tests in polymeric composites reinforced with curua fibers" (in Portuguese), In: Proceedings of the $62^{\text {nd }}$ International Congress of the Brazilian Association for Metallurgy and Materials, pp. 871-879, Vitoria, Brazil, July, 2007.

[12] MONTEIRO, S.N., MARGEM, F.M., SANTOS JR, L.F.L., "Impact tests in Polyester matrix composites reinforced with ramie fibers", Proceedings of the $63^{\text {nd }}$ International Congress of the Brazilian Association for Metallurgy and Materials., pp. 563-571, Santos, Brazil, July, 2008.

[13] FERREIRA, A.S., MONTEIRO, S.N., LOPES, F.P.D., "Analysis of the impact strength of epoxy composites reinforced with aligned curaua fibers", In: Proceedings of the $63^{\text {nd }}$ International Congress of the Brazilian Association for Metallurgy and Materials, pp. 805-813, Santos, Brazil, July, 2008.

[14] COSTA, L.L., MONTEIRO, S.N., SANTAFE JR., H.P., et al., "ACharacterization of the impact resistance of coir fiber reinforced polyester matrix composites", In: Proceedings of the $63^{\text {nd }}$ International Congress of the Brazilian Association for Metallurgy and Materials, pp. 572-580, Santos, Brazil, July, 2008.

[15] ASTM D 256-84, Standard test method for impact resistance of plastic and electrical insulating materials. USA, ASTM, September, pp. 81-102, 1984.

[16] GORE, A. An Inconvenient Truth. The Planetary Emergency of Global Warming and What We Can Do About It, Emmaus, Pennsylvania, USA, Rodale Press, 2006.

[17] SATYANARAYANA, K.G., GUIMARÃES, J.L., WYPYCH, F. "Studies on lignocellulosic fibers of Brazil. Part I: Source, production, morphology, properties and applications", Composites: Part A, v.38, pp. 1694-1709, 2007.

[18] BLEDZKI, A .K.., GASSAN, J. "Composites Reinforced With Cellulose-Based Fibers", Prog. Polym. Sci, v.4, pp. 221-274, 1999.

[19] SAHED, D.N., JOG, J.P. "Natural fiber polymer composites: a review", Advances in Polymer Technol., v. 18, 221-274, 1999.

[20] MOHANTY, A.K., MISRA, M., DRZAL, L.T. "Sustainable biocomposites from renewable resources: opportunities and challenges in the green material world", J. Polym. Environ., v.10, pp.19-26, 2002.

[21] TORRES, F.G., CUBILLAS, M.L. "Study of the interfacial properties of natural fibre reinforced polyethylene", Polymer Testing , v.24, pp. 694-698, 2005.

[22] MOHANTY, A.K., MISRA, M., HINRICHSEN, G. " Biofibers, biodegradable polymers and biocomposites: an overview”, Macromolecular Mat. And Engineering, v. 276/277, pp.1-24, 2000.

[23] AQUINO, R.C.M.P., D'ALMEIDA, J.R.M., MONTEIRO, S.N. "Flexural Mechanical Properties of Piassava Fibers (Attalea funifera)-Resin Matrix Composites", J. Mater. Sci. Letters, v. 20, pp.1017-1019, 2001.

[24] AQUINO, R.C.M.P., MONTEIRO, S.N., D'ALMEIDA, J.R.M. "Evaluation of the Critical Fiber Length of Piassava (Attalea funifera) Fibers using the Pullout Test", J. Mater. Sci. Letters, v.22, pp.1495-1497, 2003. 
[25] DEUS, J.F., MONTEIRO, S.N., D'ALMEIDA, J.R.M. "Effect of Drying, Molding Pressure, and Strain Rate on the Flexural Mechanical Behavior of Piassava (Attalea funifera Mart) Fiber-Polyester Composites", Polymer Testing, v.24, pp. 750-755, 2005.

[26] D'ALMEIDA, J.R.M., AQUINO, R.C.M.P., MONTEIRO, S. N., "Tensile Mechanical Properties, Morphological Aspects and Chemical Characterization of Piassava (Attalea funifera) Fibers", Composites. Part A, v.37 pp. 1473-1479, 2006.

[27] MONTEIRO, S.N., AQUINO, R.C.M.P., LOPES, F.P.D., et al., "Charpy Notch Toughness of Polyester Composites Reinforced with Piassava Fibers”, Matéria (R.J), v.11, n.3, pp. 204-210, 2006.

[28] CALLISTER JR, W.D., Materials Science and Engineering - An Introduction, 5 ed., New York, NY, John Wiley \& Sons, 2000.

[29] FU, S.Y., LAUKE, B., MÄDER, E., et al., "Fracture Resistance of Short-Glass-Fiber-Reinforced and Short-Carbon-Fiber-Reinforced Poly-propylene under Charpy Impact Load and Dependence on Processing", J. Mater. Process. Technol., v.89/90, pp. 501-507, 1999.

[30] LEÃO, A.L., TAN, I.H., CARASCHI, J.C. "Curaua Fiber - A Tropical Natural Fibr from Amazon Potential and Applications in Composites", Proceedings of the International Conference on Advanced Composites, Hurghada, Egypt, May, pp. 557-564, 1998.

[31] MONTEIRO, S.N., COSTA, L.L., LOPES, F.P.D. "Characterization of the impact resistance of coir fiber reinforced polyester composites", In: Proceedings of the TMS Conference, New Orleans, LA, USA, March, pp.1-6, 2008.

[32] YUE, C.Y., LOOI, H.C., QUEK, M.Y. "Assessment of Fibre-Matrix Adhesion and Interfacial Properties Using the Pullout Test", Int. J. of Adhesion and Adhesives, v. 15, pp. 73-80, 1995.

[33] SALIT, M. S. Tropical Natural Fibre Composites: Properties, Manufacture and Applications. [s.1.]: Springer, 2014.

[34] MONTEIRO, S. N., D'ALMEIDA, J.R.M. "Pullout tests in lignocellulosic fibers - A methodology of analysis" (in Portuguese), Matéria (R.J)., v. 11, n.3, pp. 189-196, 2006.

[35] CALLISTER JR, W.D., Materials Science and Engineering - An Introduction, 5 ed., New York, NY, John Wiley \& Sons, 2000.

[36] FU, S.Y., LAUKE, B., MÄDER, E., et al., "Fracture Resistance of Short-Glass-Fiber-Reinforced and Short-Carbon-Fiber-Reinforced Poly-propylene under Charpy Impact Load and Dependence on Processing", J. Mater. Process. Technol., v.89/90, pp. 501-507, 1999.

[37] MONTEIRO, S.N., AQUINO, R.C.M.P., LOPES, F.P.D., et al., "Charpy impact notch toughness of piassava fibers reinforced polyester matrix composites" (in Portuguese), Matéria (R.J)., v.11, n.3, pp.204210, 2006.

[38] MONTEIRO, S.N., COSTA, L.L., LOPES, F.P.D., et al., "Characterization of the impact resistance of coir fiber reinforced polyester composites", In: Proceedings of the TMS Conference, New Orleans, LA, USA, March, pp. 1-6, 2008.

[39] YUE, C.Y., LOOI, H.C., QUEK, M.Y. "Assessment of Fibre-Matrix Adhesion and Interfacial Properties Using the Pullout Test", Int. J. of Adhesion and Adhesives, v.15, pp. 73-80, 1995.

[40] THAKUR, V.K., THAKUR, M.K., GUPTA, R.K. "Review: Raw Natural Fiber-Based Polymer Composites", International Journal of Polymer Analysis \& Characterization, v. 19, pp. 256-271, 2014.

[41] MONTEIRO, S. N., SATYANARAYANA, K. G., LOPES, F. P. D. "High strength natural fibers for improved polymer matrix composites”, Materials Science Forum, v. 638-642, pp.961-966, 2010.

[42] ZAH, R., HISCHIER, R., LEÃO, A.L., BROWN, I. "Curaua fibers in automobile industry - A sustainability assessment", J. Cleaner Production, v.15, pp.1032-1040, 2007.

[43] ALBINANTE, S. R., PACHECO, É. B. A. V., VISCONTE, L. L. Y. "Review of chemical treatments of natural fiber for blending with polyolefins", New Chemistry, v. 36, n. 1, pp. 114-122, 2013.

[44] ALONSO, T. V., Study of the reaction of formation of adducts generated by epoxy resin and polyalkylene glycols., Degree M.Sc., Polytechnic School of the University of São Paulo, São Paulo, SP, Brasil, 2013.

[45] ROSA, N. C. G., MARTINS, L. B. S., LOPES, F. P. D., et al., Dynamic-mechanical characterization of polyester matrix composites reinforced with banana fiber, The Minerals, Metals and Materials Society, 2011. 
[46] ASIM, M., ABDAN, K., JAWAID, M., et al., "A Review on Pineapple Leaves Fibre and Its Composites”, International Journal of Polymer Science, pp.1-16, 2015.

[47] RANA, S., FANGUEIRO, R. Advanced Composite Materials for Aerospace Engineering: Processing, Properties and Applications., Woodhead Publishing, 498 p, 2016. 